\title{
Investigating the Antioxidant and Antimicrobial Activity of Artocarpus heterophyllus Lam. (Jackfruit) Latex
}

\author{
Antony V. Samrot ${ }^{1, * i D}$, Tan Chuan Sean 1(D) \\ 1 School of Bioscience, Faculty of Medicine, Bioscience and Nursing, MAHSA University, Jenjarom, Selangor 42610, \\ Malaysia \\ * Correspondence: antonysamrot@gmail.com (A.V.S.);
}

Scopus Author ID 36100751800

Received: 27.05.2021; Revised: 10.07.2021; Accepted: 15.07.2021; Published: 8.08.2021

\begin{abstract}
Plant latex is well-established as a defensive exudate against natural herbivory. However, its bioactive properties and potential use as a clinical adjunct are not fully explored in the current literature. In this study, latex was procured from Artocarpus heterophyllus Lam. (jackfruit) and subsequently evaluated for its antioxidant and antimicrobial activity. Aqueous extract (AE) and trifluoroethanol extract (TFE) of jackfruit latex were prepared using distilled water and trifluoroethanol. Both extracts were then characterized via thin-layer chromatography (TLC), ultraviolet-visible (UV-Vis) spectroscopy, and gas chromatography-mass spectrometry (GC-MS) analysis. Antimicrobial activity and antioxidant activity were determined for the extracts. Antibacterial activity was exhibited by TFE against $P$. aeruginosa, $S$. aureus, and Bacillus sp. The antioxidant activity of AE was significantly higher than TFE.
\end{abstract}

Keywords: Artocarpus heterophyllus Lam.; latex; antioxidant activity; antimicrobial activity.

(C) 2021 by the authors. This article is an open-access article distributed under the terms and conditions of the Creative Commons Attribution (CC BY) license (https://creativecommons.org/licenses/by/4.0/).

\section{Introduction}

The jackfruit is a widely known member of the breadfruit, fig, and mulberry family [1]. Originating as a regional native of Malaysia [2] and the Western Ghats of Southern India [3], the jackfruit is also actively cultivated in other tropical areas solely for its large and nutrientrich fruit. Although jackfruit is a latex-producing plant, there is not much commercial interest in its latex. Exuding from the jack tree's leaves, bark, stem, and fruits, it appears as a milkywhite fluid that is extremely sticky upon touch [4]. It coagulates on exposure to air and has a fruity aroma resembling that of bananas and pineapples [1]. In terms of its chemical composition, jackfruit latex is rich in lipid-derived waxy substances, proteins, secondary plant metabolites (i.e., tannin, alkaloids, and flavonoids), and other minerals [5]. Chemical examination by Balakrishna and Seshadri [6] found that the latex also consists of alphaartostenones (a ketone unique to Artocarpus) occurring in the form of enol-wax-esters. The high amount of resin content and gum-like properties are also notable characteristics of jackfruit latex [7].

Rare cases of anaphylactic reactions towards the latex have been documented in the existing literature, often inadvertently due to consumption of unwashed fruit or cross-reactivity of food allergens with the latex [8]. A case report by Wongrakpanich et al. [9] described how a 34-year-old female suffered from dyspnoea, facial angioedema, cough, urticaria, and chest discomfort just 15 minutes after consuming dried jackfruit. This incites the false notion 
amongst many that jackfruit latex is only harmful to humans and does not provide any beneficial boons for health. However, as reviewed by Swami et al. [10], jackfruit latex is capable of alleviating various ophthalmic ailments, pharyngitis, snakebites, and even glandular swellings. Besides that, deterioration of wound abscesses can also be mitigated by utilizing a mix of jackfruit latex and vinegar [11]. These aforementioned statements strongly support the fact that latex-bearing plants, such as that of jackfruit, are still endowed with magico-medical significance amongst indigenous tribes, as they believe that plant latex is capable of ameliorating various ailments if prepared correctly [12].

There is a very minimal description regarding the possible exploitations of jackfruit latex for medicinal uses in the existing literature. In addition, the exact chemical composition and bioactive identity of jackfruit latex are unbeknownst to many, inadvertently blurring the lines between currently established knowledge and possible applications for human welfare. Henceforth, the present study aims to investigate the bioactivity of jackfruit latex in an effort to establish its use in the medical and scientific community.

\section{Materials and Methods}

\subsection{Latex samples.}

With the use of a small blade to make incisions, $7.6 \mathrm{~g}$ of jackfruit latex was successfully acquired from the tree bark, stems, leaves, and fruits of Artocarpus heterophyllus Lam. located at Jalan Sri Sarawak 4, Klang, Selangor, Malaysia (latitude: $3^{\circ} 0^{\prime} 50.4^{\prime \prime} \mathrm{N}$ and longitude: $101^{\circ} 27^{\prime}$ 18 "E). The collected latex was stored in a glass container and subsequently kept in a hot air oven at $65^{\circ} \mathrm{C}$ for $12 \mathrm{~h}$. The dried latex was then scraped out from the container and weighed as the dry weight of the latex. After weighing, the scraped latex was immediately kept in a separate glass container (sterile) and refrigerated for storage.

\subsection{Test microorganisms.}

Four bacterial species comprising 2 Gram-negatives and 2 Gram-positives were selected to investigate the antimicrobial activity of jackfruit latex: Escherichia coli, Pseudomonas aeruginosa, Staphylococcus aureus, and Bacillus sp.

\subsection{Characterization of jackfruit latex.}

$1 \mathrm{~g}$ of latex was dissolved in $10 \mathrm{~mL}$ of dimethyl sulfoxide (DMSO) (AR grade, Fisher $^{\mathrm{TM}}$ ) to prepare $10 \%$ latex solution. $1 \mathrm{~mL}$ of the prepared $10 \%$ latex solution was then pipetted into a standard quartz glass cuvette before subjecting it for UV-Vis spectroscopy (GENESYS 10S UV-Vis). An absorption spectrum between the wavelengths of $200 \mathrm{~nm}$ to 800 $\mathrm{nm}$ was then generated for the prepared latex solution. The DMSO extract, a bipolar solvent (in order to find possible polar and nonpolar compounds), was used for analyzing it in GC-MS (QP2010 Plus) where the following criteria have been kept - column oven temperature:50.0 ${ }^{\circ} \mathrm{C}$, injection temperature: $280.00{ }^{\circ} \mathrm{C}$, injection mode: split, pressure: $49.5 \mathrm{kpa}$, total flow: 13.4 $\mathrm{ml} / \mathrm{min}$, column flow: $0.95 \mathrm{ml} / \mathrm{min}$, linear velocity: $35.3 \mathrm{~cm} / \mathrm{sec}$ purge flow: $3.0 \mathrm{ml} / \mathrm{min}$ split ratio:10.0. 


\subsection{Preparation of jackfruit latex extracts.}

The solvent extraction method was utilized to prepare two different jackfruit latex extracts [13]. For the preparation of $10 \% \mathrm{w} / \mathrm{v}$ AE / TFE, $10 \mathrm{~g}$ of dried latex was mixed with $100 \mathrm{~mL}$ of distilled water/trifluoroethanol (AR grade, R\&M Chemicals). The contents were then centrifuged at $3000 \mathrm{rpm}$ for 10 minutes. After centrifugation, the supernatant was poured into a $50 \mathrm{~mL}$ beaker while the sediments were discarded. Subsequently, the beaker was sealed with perforated aluminum foil and kept in a hot air oven $\left(24\right.$ hours, $\left.60{ }^{\circ} \mathrm{C}\right)$ to dry. The dried $\mathrm{AE}$ and TFE were then scraped out from their respective beakers and weighed separately to calculate the latex yield efficiency, according to Eqn. (1).

Latex Yield Efficiency $=\frac{\text { Dry weight of extract }\{\mathrm{g}\}}{\text { Dry weight of latex }(\mathrm{g})} \times 100 \%$

\subsection{Thin layer chromatography of latex extracts.}

Both AE and TFE were subjected to TLC [14]. 2 pieces of TLC plates measuring $2 \mathrm{~cm}$ x $8 \mathrm{~cm}$ were cut out using sterile scissors. A pencil was then used to label the origin line, approximately $1.5 \mathrm{~cm}$ apart from the bottom. A sterile wooden applicator stick was then used to gently 'scrape' the spotting area at the origin line. Using another applicator stick, the prepared $\mathrm{AE}$ was then spotted in the spotting area. Care was taken not to spot too much or too little of the extract. A small amount of methanol (AR grade, HmBG Chemicals) was poured into a 500 $\mathrm{mL}$ beaker, approximately $1 \mathrm{~cm}$ above the chamber bottom. A strip of filter paper (soaked with methanol) was then placed against the chamber wall. Using sterile forceps, the TLC plate was then placed into the TLC chamber to allow the mobile phase (methanol) to rise to the stationary phase (TLC plate). The chamber was then closed with a petri dish cover, acting as the lid. Subsequently, the TLC plate was left alone in the chamber for the development of spots. Just before the solvent reaches the uppermost end of the TLC plate, the TLC plate was removed and the solvent front (final distance traveled by the solvent) was labeled with a pencil. The plate was left to air dry before subjecting for staining. A pinch of resublimed iodine chips (AR grade, DEXO Chem) was placed into a new $500 \mathrm{~mL}$ beaker for staining. The dried TLC plate was then placed into the beaker and sealed with a petri dish cover. After leaving for staining, any visualized spots were circled with a pencil, and the distance traveled by each spot $(\mathrm{mm})$ was measured. By measuring the distance traveled by the solvent $(\mathrm{mm})$, the retention factors $\left(\mathrm{R}_{\mathrm{f}}\right.$ ) for each spot were calculated by using Eqn. (2). The procedure was repeated for TFE using similar steps, and their $R_{\mathrm{f}}$ values were also calculated.

Retention Factor $(R f)=\frac{\text { Distance travelled by spot }(\mathrm{mm})}{\text { Distance travelled by solvent }(\mathrm{mm})}$

\subsection{UV-Vis spectroscopy of latex extracts.}

$1 \mathrm{~mL}$ of AE was pipetted into a standard quartz glass cuvette before subjecting it for UV-Vis spectroscopy (Genesys $10 \mathrm{~S} \mathrm{UV}$-Vis). An absorption spectrum between the wavelengths of $200 \mathrm{~nm}$ to $800 \mathrm{~nm}$ was then generated for the prepared extract. For AE, $1 \mathrm{~mL}$ of distilled water was used as the blank. The AE was diluted in a 1:1 ratio with distilled water until maximum absorbance at a wavelength $(\lambda \max )$ of less than 1.000 was attained. 


\subsection{DPPH assay of latex extracts.}

The DPPH assay of the prepared extracts was done according to the procedure outlined by Akowuah et al. [15]. $20 \mathrm{~mL}$ of $0.1 \mathrm{mM}$ DPPH (extra pure 95\%, SRL Chemicals) was prepared with methanol as the solvent. Extract concentrations of $100-500 \mu \mathrm{g} / \mathrm{mL}$ for both AE and TFE were prepared via simple dilution, starting from a stock concentration of $500 \mu \mathrm{g} / \mathrm{mL}$. The stock solutions were prepared by mixing 0.05 grams of a dried extract with $100 \mathrm{~mL}$ of its corresponding solvent (distilled water or trifluoroethanol). Each prepared extract concentration was then diluted again with methanol in a 1:5 ratio: $200 \mu 1$ of an extract with $800 \mu 1$ methanol. $2 \mathrm{~mL}$ of the prepared DPPH-methanolic solution was then pipetted to each of the diluted extract concentrations. The mixtures were then mixed with a stirring glass rod and subsequently kept under a shade for an hour. A negative control is simulated by pipetting $2 \mathrm{~mL}$ of DPPHmethanolic solution to $1 \mathrm{~mL}$ of methanol. Using a UV-Vis spectrophotometer (GENESYS 10S UV-Vis), three absorbance readings were measured at $517 \mathrm{~nm}$ for each extract concentration. The mean absorbance readings for each extract concentration were then obtained and incorporated onto Eqn. (3) to calculate the DPPH radical scavenging activity (\%). A graph was then plotted (for $\mathrm{AE}$ and TFE) to illustrate the relationship between the concentration of extracts $(\mu \mathrm{g} / \mathrm{mL})$ and their respective DPPH scavenging activities $(\%)$.

$$
\text { DPPH scavenging activity (\%): } \frac{\text { (Absorbance of Control-Absorbance of Sample }}{\text { Absorbance of Control }} \times 100
$$

\subsection{Phosphomolybdenum assay of latex extracts.}

Phosphomolybdenum assay was done according to the revised procedures outlined by Saha et al. [16], which was first proposed by Prieto et al. [17]. To prepare the reagent solution, 0.6M of concentrated sulphuric acid (95-97\% EMSURE®, Merck Chemicals) was mixed with $4 \mathrm{mM}$ of ammonium molybdate (pure 98\%, SRL Chemicals). $28 \mathrm{mM}$ of sodium dihydrogen phosphate (EMSURE®, Merck Chemicals) was then added into the mixture and stirred with a stirring glass rod. $3 \mathrm{~mL}$ of the prepared solution was then pipetted into separate test tubes. Subsequently, $0.3 \mathrm{~mL}$ of each of the different extract concentrations prepared earlier (100 - 500 $\mu \mathrm{g} / \mathrm{mL}$ ) were separately pipetted into the test tubes. For the negative control (blank), $0.3 \mathrm{~mL}$ of methanol was added instead of the latex extract. All the test tubes were then incubated in the hot air oven at $95{ }^{\circ} \mathrm{C}$ for 90 minutes. After cooling to room temperature, each of the test mixtures' absorbance was measured at $695 \mathrm{~nm}$. A graph was then plotted (for AE and TFE) to illustrate the relationship between the concentration of extracts $(\mu \mathrm{g} / \mathrm{mL})$ and their respective absorbance readings at $695 \mathrm{~nm}$ (a.u.).

\subsection{Agar well diffusion assay of latex extracts.}

Before carrying out the agar well diffusion assay, extract concentrations ranging from $500-2000 \mu \mathrm{g} / \mathrm{mL}$ for both AE and TFE were prepared by simple dilution, starting from a stock concentration of $2000 \mu \mathrm{g} / \mathrm{mL}$. The stock solutions were prepared by mixing 0.2 grams of the dried extract with $100 \mathrm{~mL}$ of its corresponding solvent (distilled water or trifluoroethanol). Agar well diffusion assay was done according to the procedures outlined by Purkayastha and Dahiya [18]. Using sterile cotton swabs, inoculums of 4 selected bacteria (E. coli, $P$. aeruginosa, S. aureus, and Bacillus sp.) were spread evenly on 2 sets of 4 nutrient agar (HiMedia) plates (total of 8 plates). The plates for AE were labeled as $\mathbf{A}, \mathbf{B}, \mathbf{C}$, and $\mathbf{D}$ while the plates for TFE were labeled as E, F, G and $\mathbf{H}$. Wells measuring $8 \mathrm{~mm}$ in diameter were 
then aseptically punched into the agar with a gel puncher ( 6 equidistant wells per agar plate). Subsequently, $10 \mu \mathrm{L}$ of the different extract concentrations were pipetted into the wells in an anti-clockwise manner. For the positive control, $5 \mu \mathrm{g}$ of ciprofloxacin disc was used for all the agar plates. $10 \mu \mathrm{L}$ of distilled water was used as the negative control for $\mathrm{AE}$, whilst $10 \mu \mathrm{L}$ of trifluoroethanol was used for TFE. The latex extracts were left to diffuse in the agar at room temperature for 2 hours. All the agar plates were then incubated (upright position) at $37{ }^{\circ} \mathrm{C}$ for 24 hours. Post-incubation, the inhibitory zone diameters to the nearest millimeter $(\mathrm{mm})$ were measured and tabulated.

\section{Results and Discussion}

\subsection{Characterization of jackfruit latex.}

UV-Vis spectrum of dried latex mixed in DMSO is shown in Figure 1. As apparent from the single sharp peak observable in the spectrum, the maximum absorbance ( $\lambda$ max) was achieved at $290 \mathrm{~nm}$. This denotes that the latex compounds' compounds maximally absorb wavelengths of light within the ultraviolet B (UVB) band (280-315 nm).

GC-MS analysis of latex demonstrated the presence of 1,2-benzoldicarbonsaeure, di(he) at RT - 20.704 as a major peak (Figure 2). Similar findings were reported in the ethanolic extracts of Caralluma indica and Brassica oleracea var. capitata f. rubra [19, 20].

\subsection{Extraction of compounds from jackfruit latex.}

The latex yield efficiency for AE was calculated to be $15.26 \%$, whilst the latex yield efficiency for TFE was $45.53 \%$. The yield for TFE was much higher than AE, denoting that more nonpolar compounds were extracted from the dried latex (Table 1). Yield from Euphorbia antiquorum and Calatropis gigantea was obtained as $91.05 \%$ and $59.47 \%$ respectively in earlier studies [21].

Table 1. Dry weights (g) and latex yield efficiencies (\%) of AE and TFE.

\begin{tabular}{c|c} 
Extract & Latex yield efficiency (\%) \\
\hline AE & 15.26 \\
\hline TFE & 45.53
\end{tabular}

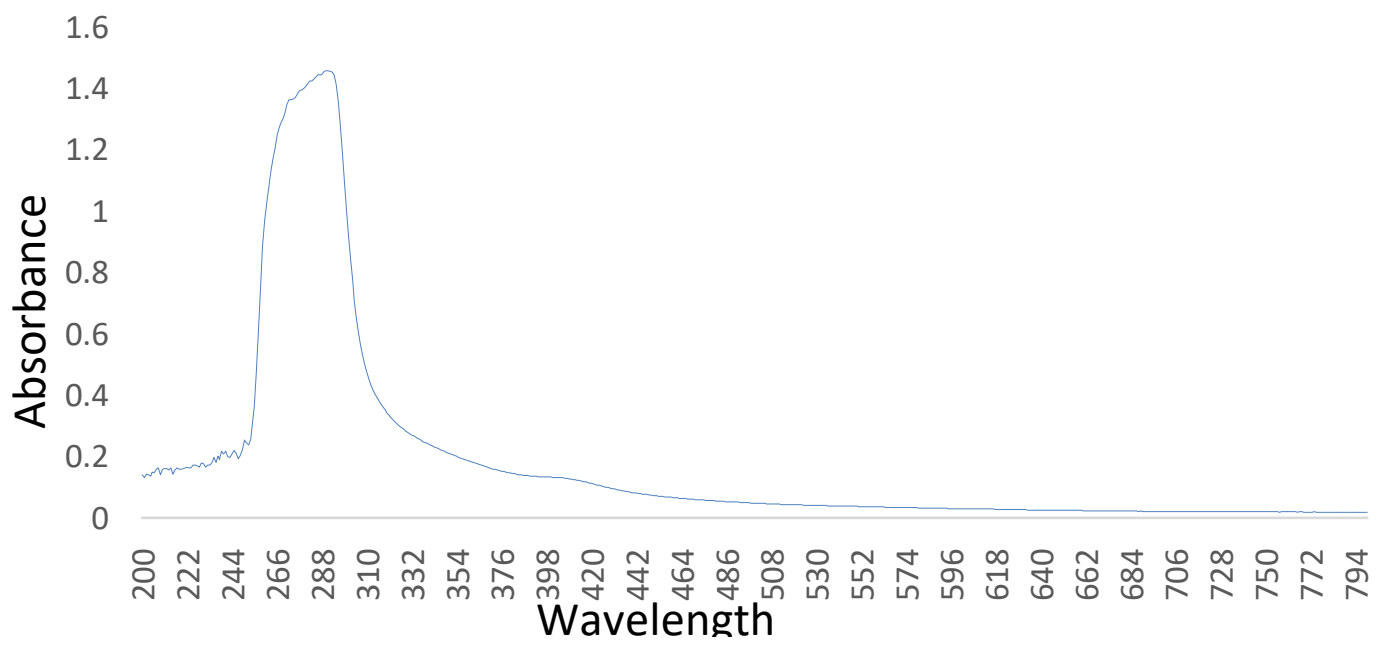

Figure 1. UV-Vis spectrum of jackfruit latex. 


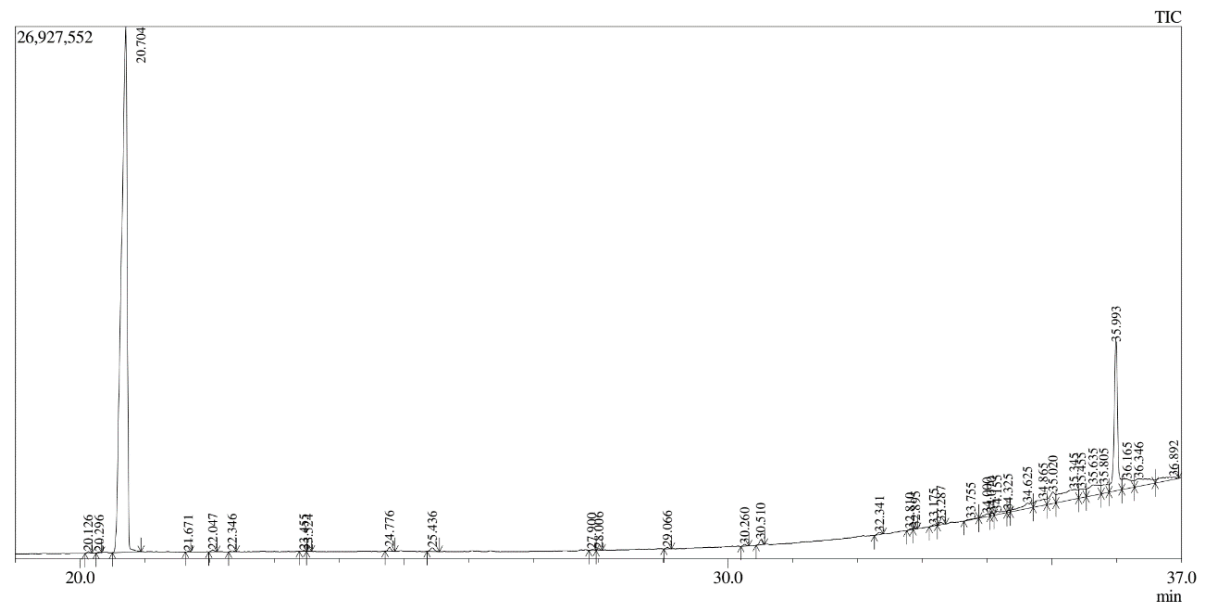

Figure 2. GC-MS analysis of jackfruit latex.

\subsection{Characterization of jackfruit latex extracts.}

As compared to the spectrum obtained for the dried latex, the UV-Vis spectrum for AE (Figure 3) shows a significant shift to the left. As evident from the decrease in $\lambda \max (200 \mathrm{~nm}$ vs. $290 \mathrm{~nm}$ ), the compounds in AE absorb lower wavelengths of light at a higher frequency. Besides that, the blunt absorption peak between 250 and $350 \mathrm{~nm}$ contrasts with the sharp peak previously observed in Figure 1. With reference from (Figure 4), the decrease in $\lambda \max (269$ $\mathrm{nm}$ vs. $290 \mathrm{~nm}$ ) also signifies that the compounds in TFE absorb lower wavelengths of light at a higher frequency. A sharp peak (albeit of lower absorbance) was also observed at $290 \mathrm{~nm}$, suggesting that some of the compounds in the dried latex lie in the aromatic range of carbonyl groups $(\mathrm{C}=\mathrm{O})$.

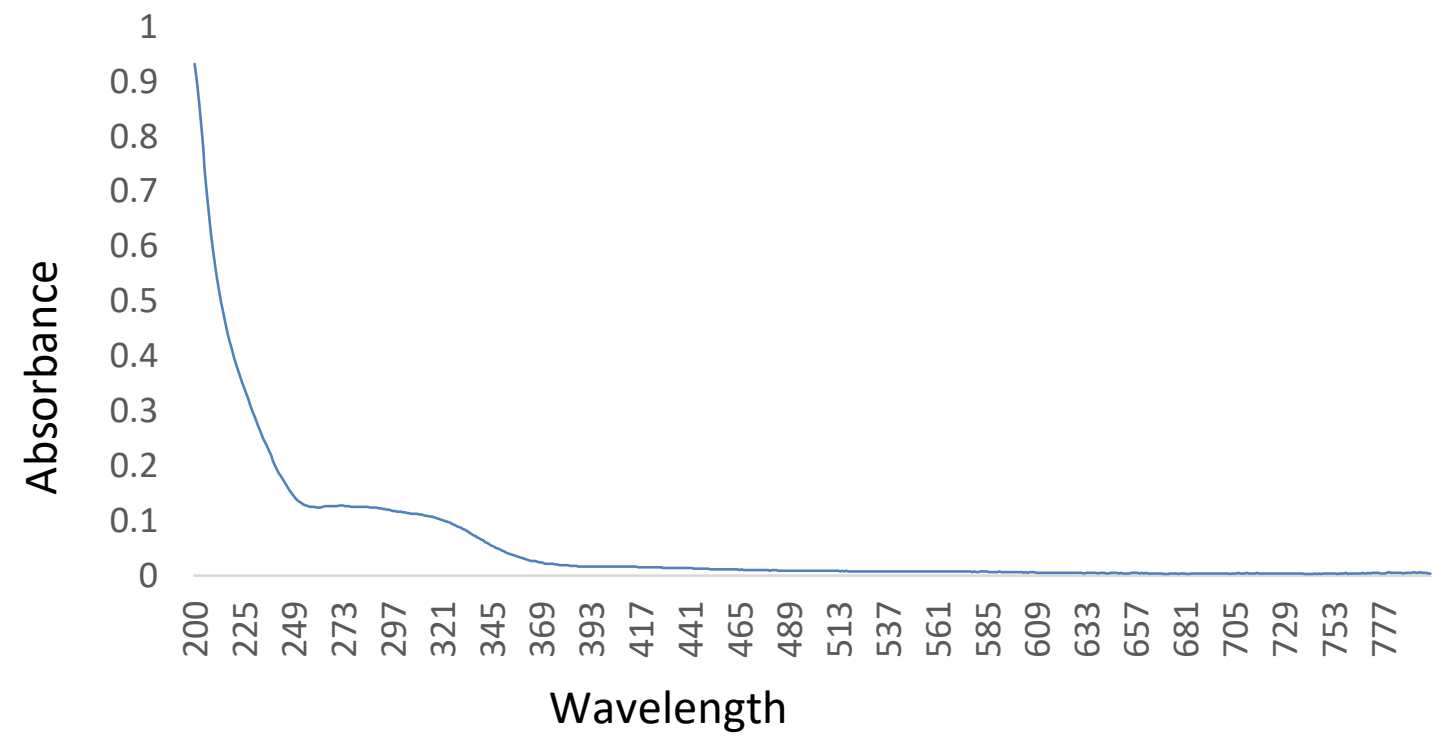

Figure 3. UV-Vis spectrum of AE with distilled water as the blank.

After performing TLC for AE, there were 4 different spots visibly separated from one another (Figure 5). With reference to Table 2, the distance traveled by spots 1, 2, 3, and 4 were measured to be $7 \mathrm{~mm}, 21 \mathrm{~mm}, 50 \mathrm{~mm}$, and $60 \mathrm{~mm}$, respectively. As the solvent (methanol) traveled a total distance of $70 \mathrm{~mm}$, the retention factors of spots 1 to 4 were calculated to be $0.10,0.30,0.71$, and 0.86 , respectively. 


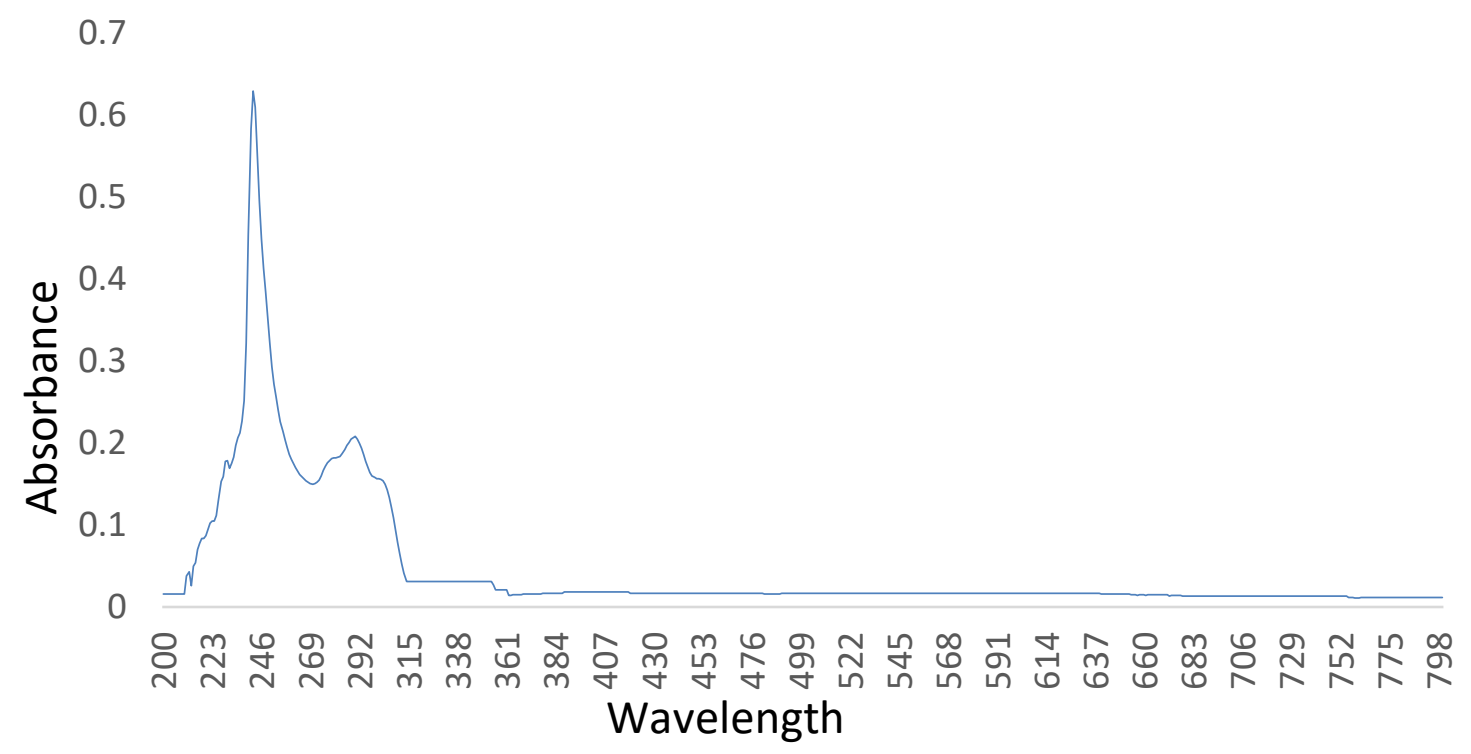

Figure 4. UV-Vis spectrum of TFE with trifluoroethanol as the blank.

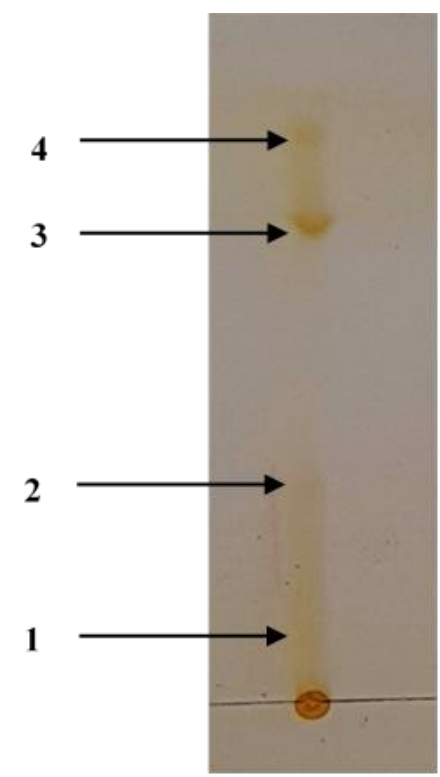

Figure 5. TLC of AE using methanol as a solvent; stained with iodine.

Table 2. Distance traveled (mm) by solvent and separated spots with their calculated $\mathrm{R}_{\mathrm{f}}(\mathrm{AE})$.

\begin{tabular}{c|c|c} 
Identity & Distance travelled $(\mathbf{m m})$ & $\mathbf{R}_{\mathbf{f}}$ \\
\hline Solvent & 70 & - \\
\hline Spot 1 & 7 & 0.10 \\
\hline Spot 2 & 21 & 0.30 \\
\hline Spot 3 & 50 & 0.71 \\
\hline Spot 4 & 60 & 0.86
\end{tabular}

After subjecting TFE to TLC, it can be inferred that there were only 2 different 'spots' visibly separated from one another (Figure 6). With reference to Table 3, the distance traveled by spots 1 and 2 was measured to be $53 \mathrm{~mm}$ and $62 \mathrm{~mm}$, respectively. As the solvent (methanol) traveled a total distance of $70 \mathrm{~mm}$, the retention factors of spots 1 and 2 were calculated to be 0.76 and 0.89 , respectively. The similarity in $\mathrm{R}_{\mathrm{f}}$ values between spot 3 and 4 of $\mathrm{AE}$; and spot 1 and 2 of TFE may be due to the result of isomers having structural similarity but with different 
functional groups, resulting in differences in polarity. This allows them to be separated during solvent extraction with distilled water as well as trifluoroethanol.

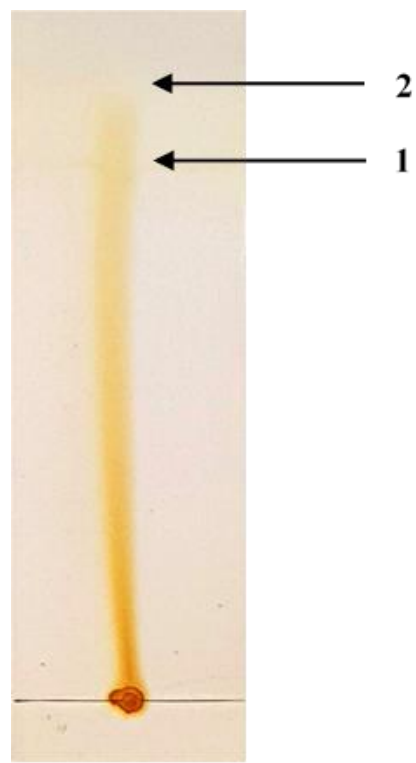

Figure 6. TLC of TFE using methanol as a solvent; stained with iodine.

Table 3. Distance traveled (mm) by solvent and separated spots with their calculated $\mathrm{R}_{\mathrm{f}}(\mathrm{TFE})$.

\begin{tabular}{c|c|c} 
Identity & Distance travelled $(\mathbf{m m})$ & $\mathbf{R}_{\mathbf{f}}$ \\
\hline Solvent & 70 & - \\
\hline Spot 1 & 53 & 0.76 \\
\hline Spot 2 & 62 & 0.89
\end{tabular}

3.4. Antioxidant activity of jackfruit latex extracts.

Figure 7 shows the relationship between different jackfruit latex extract concentrations $(\mu \mathrm{g} / \mathrm{mL})$ and DPPH scavenging activity $(\%)$.

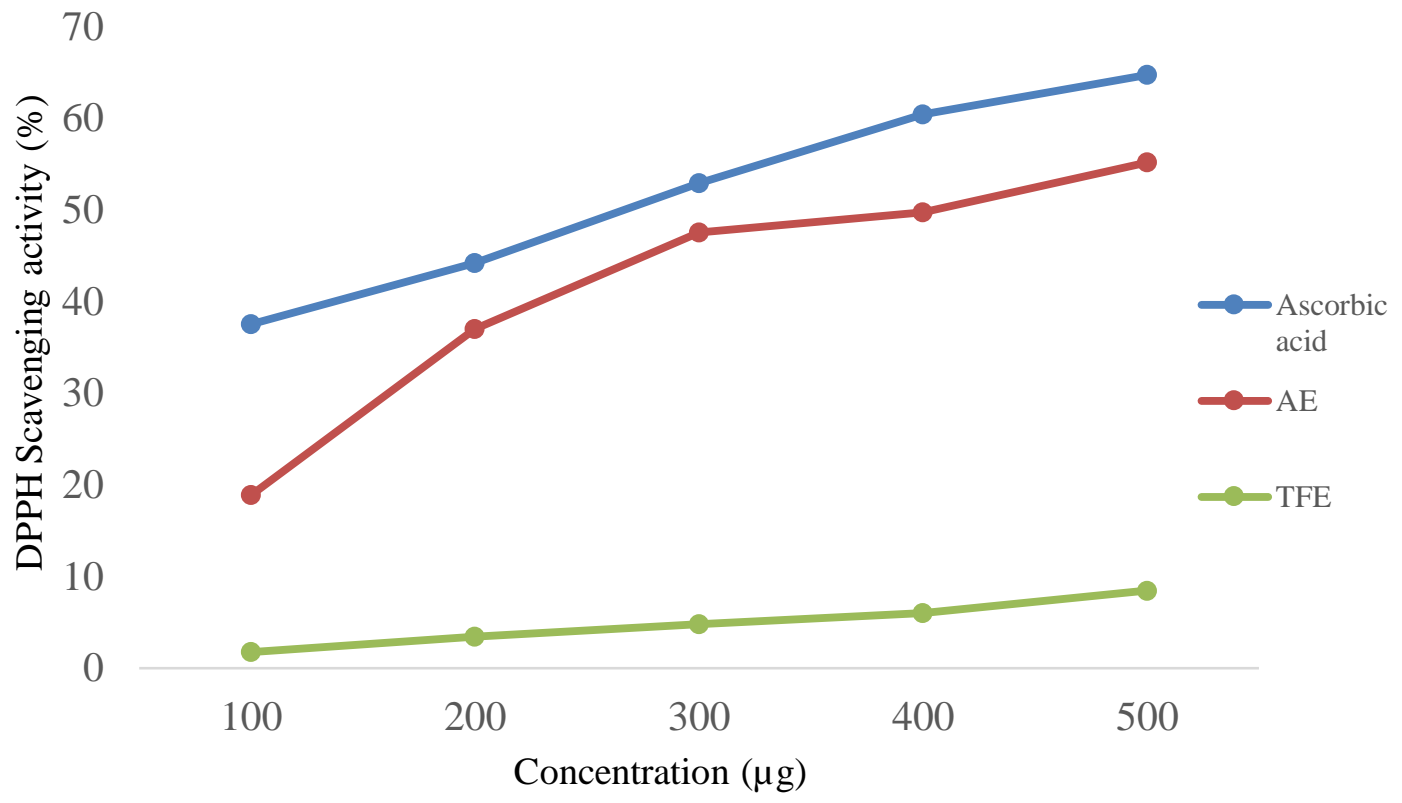

Figure 7. DPPH scavenging activity (\%) of jackfruit extracts. 
At $100 \mu \mathrm{g} / \mathrm{mL}$, the DPPH scavenging activity of ascorbic acid, AE, and TFE were found to be $37.53 \pm 1.04,18.89 \pm 1.20$ and $1.76 \pm 0.19$ respectively, whilst the DPPH scavenging activity of ascorbic acid, AE, and TFE at $500 \mu \mathrm{g} / \mathrm{mL}$ were $64.72 \pm 0.80,55.17 \pm 1.10$ and $8.47 \pm 1.16$ respectively. More DPPH radicals were evidently scavenged by $500 \mu \mathrm{g} / \mathrm{mL}$ of AE and TFE (linear increments per $100 \mu \mathrm{g} / \mathrm{mL}$ of extracts). This signifies that the DPPH scavenging activity increases as the concentration of the extracts increases. Although the antioxidant activity of TFE showed an increasing trend, it is much lower than AE at all concentrations.

Figure 8 shows the results of the phosphomolybdenum assay, depicting the relationship between different jackfruit latex extract concentrations $(\mu \mathrm{g} / \mathrm{mL})$ and absorbance at $695 \mathrm{~nm}$. At $100 \mu \mathrm{g} / \mathrm{mL}$, ascorbic acid, AE, and TFE had an absorbance reading of $0.343 \pm 0.002$, $0.156 \pm 0.002$, and $0.024 \pm 0.003$ respectively, whilst the absorbance reading for ascorbic acid, $\mathrm{AE}$, and TFE at $500 \mu \mathrm{g} / \mathrm{mL}$ were $1.095 \pm 0.008,0.735 \pm 0.003$, and $0.118 \pm 0.003$, respectively. The linear increase in absorbance readings from 100 to $500 \mu \mathrm{g} / \mathrm{mL}$ reinforces the findings from the DPPH assay. Similarly, TFE demonstrated the lowest absorbance readings at all concentrations.

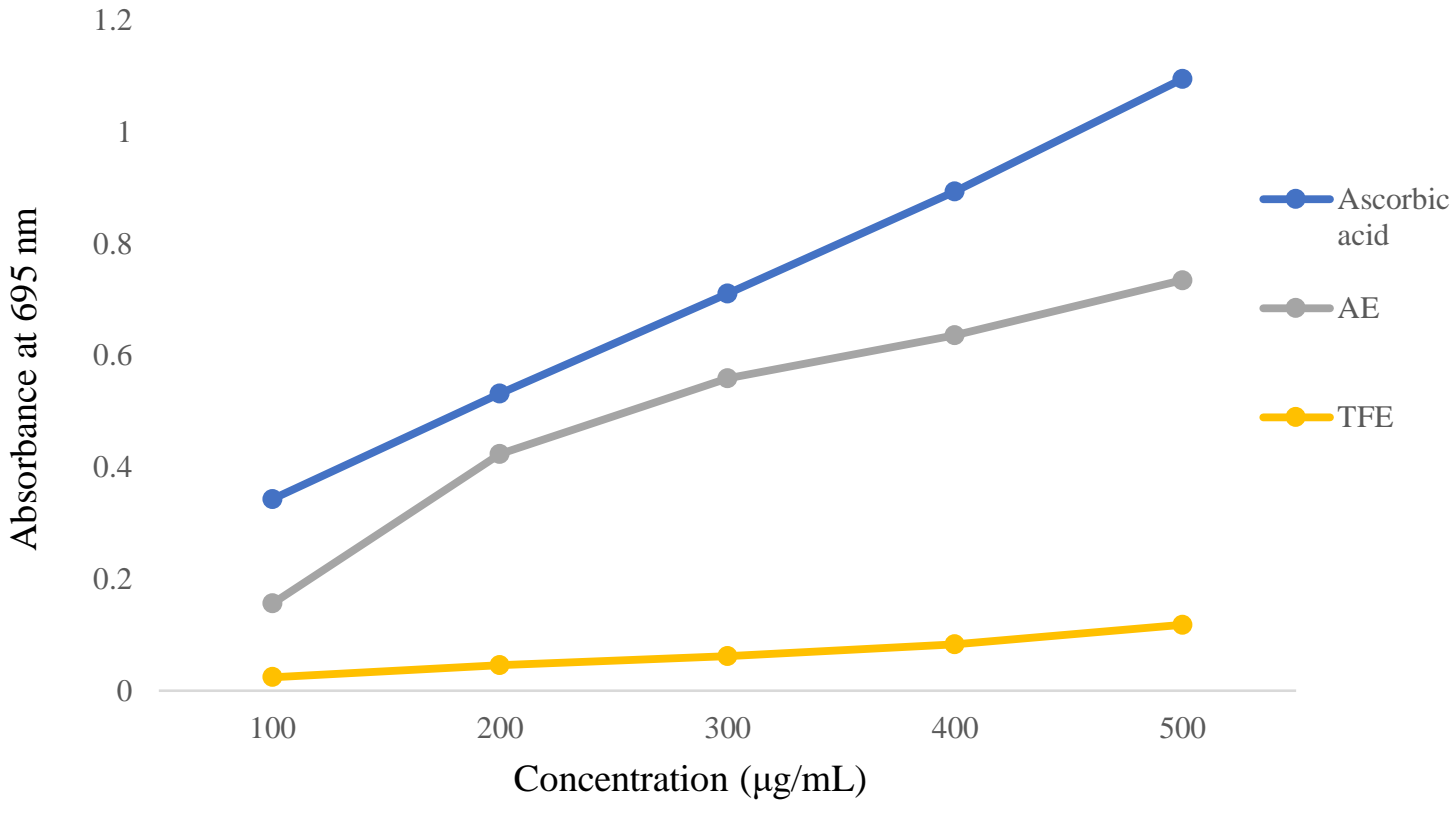

Figure 8. Phosphomolybdenum assay of jackfruit extracts.

Unraveling the bioactive capacity of jackfruit latex has been the forefront objective of many researchers and scholars alike. As evident from the antioxidant findings in the present study, linear relationships were apparent as the concentration of the jackfruit latex extract increases. From the DPPH and phosphomolybdenum essay, it can be inferred that the antioxidant activity of AE is on par with that of ascorbic acid, bearing values of proximity. This coincides with the recent findings by Sundarrajan and Pottail [5], as they found that the $\%$ inhibition of DPPH by jackfruit latex is comparable to that of ascorbic acid, with the lowest inhibition difference being approximately $20 \%$. As inferred by the authors, the aforementioned trend is plausibly attributed to the polyphenol, alkaloid, flavonoid, and tannin content in the latex, which was well-established to have significant levels of radical scavenging efficiency [22- 24]. As surmised by Asfar et al. [25], these phyto-antioxidants proceed in a linear bioefficient mechanism; free radicals are actively reduced via electron donation, effectively 
hindering their capacity to inflict oxidative stress (and ultimately cell damage). Besides that, the abundance of $\alpha$-artostenone in jackfruit latex should also be acknowledged, plausibly attributing to its antioxidant activity [6]. As this compound exists freely as enol-wax-esters, they are thus composed of fatty acids and fatty alcohols, which are known to confer antioxidant activity. An in vitro study by Shahinuzzaman et al. [26] affirms the aforementioned statement as they found that the latex of Ficus carica (fig) demonstrated high levels of antioxidant activity. Additionally, findings from Zhang et al. [27] elucidated the capacity of ascorbate, thiols, and tocotrienol to confer antioxidant activity in the latex of Hevea brasiliensis. These compounds may also be present in the latex of jackfruit, which must be unraveled in future studies.

The antioxidant capacity of jackfruit latex can be reinforced by relating to studies done on other latex-producing plants. A study by Aljane et al. [28] found varying levels of antioxidant activity among various fig ecotypes before concluding that figs are appreciable sources of natural antioxidants. As the latex of figs was also determined to confer antioxidant activity [26], the possibility that jackfruit latex possesses antioxidant activity should not be overlooked. Devi et al. [29] reviewed the antioxidant capacity of many different parts of jackfruit is well-acknowledged. As such, present findings of antioxidant activity in jackfruit latex were to be expected. To further reinforce, the antioxidant activity of Aloe schelpei latex was evidently determined by Teka and Kassahun [30], in which the antioxidant capacity of Aloe variants was already well-acknowledged in the existing literature [31, 32]. Similar findings were also apparent for other latex-producing plants, including studies on Euphorbia dendroides [33] and Carica papaya [34].

\subsection{Antimicrobial activity of jackfruit latex extracts.}

Figure 9 shows the agar plates after performing agar well diffusion assay on AE ( 0 $2000 \mu \mathrm{g} / \mathrm{mL}$ ). With reference to Table 4 , the positive control ( $5 \mu \mathrm{g}$ of ciprofloxacin) was the only well with a visible zone of inhibition (ranging from 24-29 mm). Increasing the concentration of $\mathrm{AE}$ does not influence its antimicrobial capacity, as evident from the absence of inhibitory zones $(0 \mathrm{~mm})$ in all the wells diffused with AE. Plates A-D swabbed with $S$. aureus, Bacillus sp., E. coli, and $P$. aeruginosa, respectively were resistant to the extract concentrations.
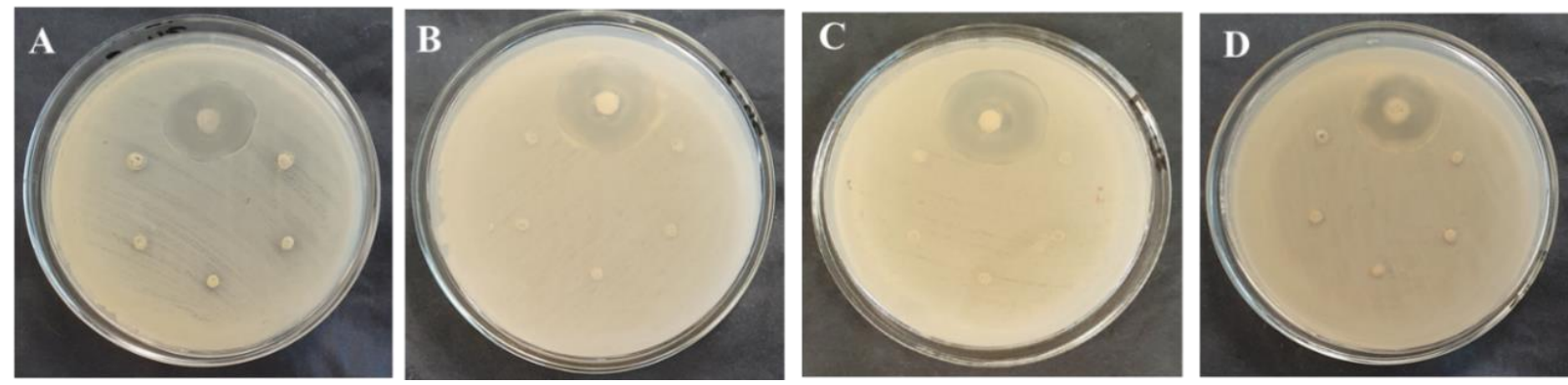

Figure 9. Agar well diffusion results for AE; (A) S. aureus; (B) Bacillus sp.; (C) E. coli; (D) P. aeruginosa.

On the other hand, Figure 10 shows the agar plates after performing agar well diffusion assay on TFE $(0-2000 \mu \mathrm{g} / \mathrm{mL})$. With reference to Table 5, increasing the concentration of TFE does influence its antimicrobial capacity, as evident from the inhibitory zones visible surrounding the wells. The inhibitory zones were observed at the highest concentration of TFE. For instance, plate $\mathbf{H}$ had inhibitory zones measuring $6 \mathrm{~mm}$ for $2000 \mu \mathrm{g} / \mathrm{mL}$ of TFE. E. coli (plate G) was found to be resistant to TFE. 
Table 4. Inhibitory zone diameters of $S$. aureus, Bacillus sp., E. coli, and P. aeruginosa plates inoculated with ciprofloxacin $(5 \mu \mathrm{g})$ and $\mathrm{AE}$ of increasing concentration $(0-2000 \mu \mathrm{g} / \mathrm{mL})$.

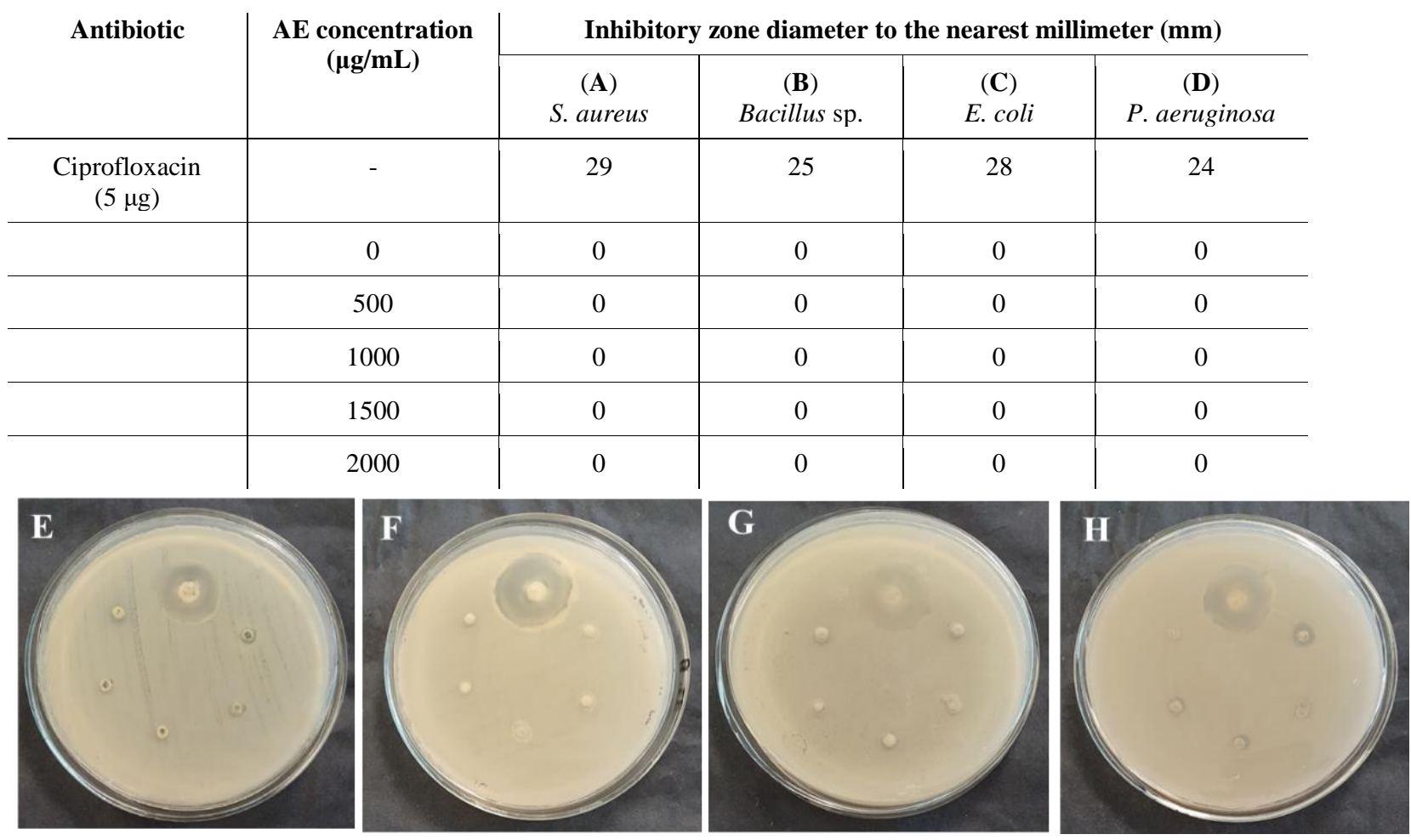

Figure 10. Agar well diffusion results for TFE; (E) S. aureus; (F) Bacillus sp.; (G) E. coli; (H) P. aeruginosa.

Table 5. Inhibitory zone diameters of $S$. aureus, Bacillus sp., E. coli, and P. aeruginosa plates inoculated with ciprofloxacin $(5 \mu \mathrm{g})$ and TFE of increasing concentration $(0-2000 \mu \mathrm{g} / \mathrm{mL})$.

\begin{tabular}{|c|c|c|c|c|c|}
\hline \multirow[t]{2}{*}{ Antibiotic } & \multirow{2}{*}{$\begin{array}{l}\text { TFE } \\
\text { concentration } \\
(\mu \mathrm{g} / \mathbf{m L})\end{array}$} & \multicolumn{4}{|c|}{ Inhibitory zone diameter to the nearest millimeter $(\mathbf{m m})$} \\
\hline & & $\begin{array}{l}\text { (E) } \\
\text { S. aureus }\end{array}$ & $\begin{array}{l}(\mathbf{F}) \\
\text { Bacillus sp. }\end{array}$ & $\begin{array}{l}\text { (G) } \\
\text { E. coli }\end{array}$ & $\begin{array}{l}\text { (H) } \\
\text { P. aeruginosa }\end{array}$ \\
\hline \multirow{6}{*}{$\begin{array}{l}\text { Ciprofloxacin } \\
(5 \mu \mathrm{g})\end{array}$} & - & 27 & 30 & 28 & 25 \\
\hline & 0 & 0 & 0 & 0 & 0 \\
\hline & 500 & 0 & 0 & 0 & 0 \\
\hline & 1000 & 0 & 0 & 0 & 0 \\
\hline & 1500 & 0 & 0 & 0 & 3 \\
\hline & 2000 & 3 & 2 & 0 & 6 \\
\hline
\end{tabular}

The antimicrobial capacity of jackfruit latex was made apparent from the agar well diffusion assay in the present study. This is evident from the linear increase in inhibitory zones in wells pipetted with increasing concentrations of the trifluoroethanol extract. This coincides with the findings obtained by Sundarrajan and Pottail [5], as the incorporation of jackfruit latex onto bimetallic silver-gold nanoparticles significantly improved the contraption's antimicrobial activity. Various postulations regarding the antimicrobial capacity of jackfruit latex have been theorized in the existing literature, including the role of proteinaceous enzymes. Siritapetawee et al. [35] successfully isolated a 48-kDa antimicrobial serine protease from jackfruit latex, which was then found to be capable of inhibiting the growth of P. aeruginosa and Candida albicans. These findings were reinforced by atomic force microscopy (AFM) images of cell 
suspensions treated with the purified protease, which significantly altered the normal morphology of $P$. aeruginosa.

The resin content of jackfruit latex may also be attributed to its antimicrobial activity [7]. A study by Shuaib et al. [36] found that resin-rich methanolic extracts (RRMEs) of Commiphora myrrha and Pinus roxburghii could inhibit the growth of Staphylococcus aureus and Bacillus subtilis, with minimal sensitivity against Gram-negative bacteria. This coincides with the findings from the present study, as E. coli was found to be resistant to the trifluoroethanol extract of jackfruit latex. However, this does not apply to $P$. aeruginosa as it was found to be the most sensitive amongst the 4 bacterial strains tested. To reinforce, a review by Bahmani et al. [37] documented that the phytochemicals of medicinal plants (e.g., carvacrol, limonene, borneol, linalool) were capable of inhibiting pseudomonal growth due to their hydrophobic nature. These chemicals can separate lipids from bacterial cell walls, causing membrane instability, thereby leading to ion expelling an electron imbalance. However, E. coli can resist the aforementioned biomechanism. As evident from a study by Keweloh et al. [38], E. coli responds to such stressors by modifying the fatty acid composition in their lipid membranes, allowing them to resist oxidative damage [39]. This reinforces the absence of inhibitory zones for E. coli as it was for this study.

The antimicrobial activity of other jackfruit parts (e.g., seeds and leaves) are wellacknowledged in the existing literature. To reinforce, Eve et al. [40] determined the antibacterial capacity of jackfruit seeds on various diarrhea-inducing bacteria. The leaves of jackfruit were also found to exhibit antifungal activity, a feat made possible by VázquezGonzález and colleagues [41]. A study in Malaysia found that essential oils extracted from jackfruit seeds exhibited antibacterial activity, along with satisfactory radical scavenging capacity (via DPPH assay) [42]. Since so many other parts of jackfruit exhibit antimicrobial activity, the antimicrobial capacity of jackfruit latex extracts can be generalized to a small extent. Latex from other plant species, including Jatropha sp. [43] and Euphorbia heterophylla [44], showed appreciable antimicrobial activity, a relationship that is also apparent in the present study done on jackfruit latex.

\section{Conclusions}

As a concluding statement, it is evident that jackfruit latex possesses bioactive properties. Antioxidant activity was found in both AE and TFE, while antimicrobial activity was found only in TFE. These findings could propel future studies to pinpoint the exact biological molecules involved in the aforesaid bioactivities. This can also pave the way for a paradigm shift regarding the bio-significance of jackfruit latex for human applications, ultimately improving its commercial, medical, and scientific interest.

\section{Funding}

This research received no external funding.

\section{Acknowledgments}

The authors wish to express their sincere gratitude to the School of Biosciences, MAHSA University, for providing the necessary lab facilities, chemicals, reagents, disposables, and equipment to conduct this study. 


\section{Conflicts of Interest}

The authors declare no conflict of interest.

\section{References}

1. Morton, J. Jackfruit. Fruits of warm climates 1987, 58-64.

2. Kassim, N.; Hambali, K.; Amir, A. Nutritional Composition of Fruits Selected by Long-Tailed Macaques (Macaca fascicularis) in Kuala Selangor, Malaysia. Trop. Life Sci. Res. 2017, 28, 91-101, https://doi.org/10.21315/tlsr2017.28.1.6.

3. Jagadeesh, S.L.; Reddy, B.S.; Swamy, G.S.K.; Gorbal, K.; Hegde, L.; Raghavan, G.S.V. Chemical composition of jackfruit (Artocarpus heterophyllus Lam.) selections of Western Ghats of India. Food Chem. 2007, 102, 361-365, https://doi.org/10.1016/j.foodchem.2006.05.027.

4. Garner, R.J.; Chaudhri, S.A. The propagation of tropical fruit trees. United Nations Food and Agricultural Organization: Rome, Italy, 1985.

5. Sundarrajan, K.S.; Pottail, L. Green synthesis of bimetallic Ag@Au nanoparticles with aqueous fruit latex extract of Artocarpus heterophyllus and their synergistic medicinal efficacies. Appl. Nanosci. 2021, 11, 971981, https://doi.org/10.1007/s13204-020-01657-8.

6. Balakrishna, K.J.; Seshadri, T.R. Chemical examination of Jack tree latex and Jack fruit gum. Proc. Indian Acad. Sci. Section A 1947, 26, 46, https://doi.org/10.1007/BF03170948.

7. Nepacina, M.; Linis, V.; Janairo, J. Physical Characterization of Latex from Artocarpus heterophyllus Lam. (Jackfruit) and Four Related Artocarpus spp. Key Eng. Mater. 2020, 833, 107-117, https://doi.org/10.4028/www.scientific.net/KEM.833.107.

8. Kabir, S.; Fatteh, S. Jackfruit Induced Anaphylaxis Associated Birchpollen-Related Food Allergies. Ann. Allergy Asthma Immunol. 2018, 121, S120, https://doi.org/10.1016/j.anai.2018.09.398.

9. Wongrakpanich, S.; Klaewsongkram, J.; Chantaphakul, H.; Ruxrungtham, K. Jackfruit anaphylaxis in a latex allergic patient. Asian Pac. J. Allergy Immunol. 2015, 33, 65-68, https://doi.org/10.12932/AP0416.33.1.2015.

10. Swami, S.B.; Thakor, N.J.; Haldankar, P.M.; Kalse, S.B. Jackfruit and Its Many Functional Components as Related to Human Health: A Review. Compr. Rev. Food Sci. Food Saf. 2012, 11, 565-576, https://doi.org/10.1111/j.1541-4337.2012.00210.x.

11. Haq, N. Fruits for the Future 10. Jackfruit (Artocarpus heterophyllus). Southampton Centre for Underutilised Crops: Southampton, England, 2006; p. 192.

12. Abarca, L.F.S..; Klinkhamer, P.G.L.; Choi, Y.H. Plant Latex, from Ecological Interests to Bioactive Chemical Resources. Planta Med. 2019, 85, 856-868, https://doi.org/10.1055/a-0923-8215.

13. Ramirez-Cadavid, D.A.; Cornish, K.; Hathwaik, U.; Kozak, R.; McMahan, M.; Michel, F.C. Development of novel processes for the aqueous extraction of natural rubber from Taraxacum kok-saghyz (TK). J. Chem. Technol. Biotechnol., 2019, 94, 2452-2464, https://doi.org/10.1002/jctb.6027.

14. Samrot, A.; Selvarani, J.; Durga, A.; Lavanya, P.; Lavanya, J.; Paulraj, J.; Petchi, I. A Handbook on Phytochemical extraction, screening and its in-vitro bioactivity assays. SARAS Publisher: Nagercoil, India, 2020.

15. Akowuah, G.A.; Ismail, Z.; Norhayati, I.; Sadikun, A. The effects of different extraction solvents of varying polarities of polyphenols of Orthosiphon stamineus and evaluation of the free radical-scavenging activity. Food Chem. 2005, 93, 311-317, https://doi.org/10.1016/j.foodchem.2004.09.028.

16. Saha, M.R.; Hasan, S.M.R.; Akter, R.; Hossain, M.M.; Alam, M.S.; Alam, M.A.; Mazumder, M.E.H. In vitro free radical scavenging activity of methanol extract of the leaves of Mimusops elengi Linn. Bangladesh J. Vet. Med. 2008, 6, 197-202, https://doi.org/10.3329/bjvm.v6i2.2336.

17. Prieto, P.; Pineda, M.; Aguilar, M. Spectrophotometric quantitation of antioxidant capacity through the formation of a Phosphomolybdenum Complex: Specific application to the determination of vitamin E. Anal. Biochem. 1999, 269, 337-341, https://doi.org/10.1006/abio.1999.4019.

18. Purkayastha, S.; Dahiya, P. Phytochemical screening and antimicrobial activity of some medicinal plants against multi-drug resistant bacteria from clinical isolates. Indian J. Pharm. Sci. 2012, 74, 443-450, https://doi.org/10.4103/0250-474x.108420.

19. Gnanashree, G.; Sirajudeen, P.M. Determination of bioactive compounds in ethanolic extract of Caralluma indica using GCMS technique. J. Pharmacogn. Phytochem. 2018; 7, 1675-1677. 
20. Rajamani, L. Phytochemical and Gc-Ms analysis of Brassica oleracea var. capitata f. rubra. World J. Pharm. Res. 2018, 7, $1392-1400$.

21. Samrot, A.V.; Sahiti, K.; Bhavya, K.S.; Suvedhaa B. Synthesis of Plant Latex Based Hybrid Nanocarriers Using Surfactants for Curcumin Delivery. J Clust Sci. 2019. 30, 281-296 https://doi.org/10.1007/s10876018-1472-5

22. Kasote, D. M.; Katyare, S. S.; Hegde, M. V.; Bae, H. Significance of antioxidant potential of plants and its relevance to therapeutic applications. Int. J. Biol. Sci. 2015, 11, 982-991, https://doi.org/10.7150\%2Fijbs.12096.

23. Hussain, T.; Tan, B.; Yin, Y.; Blachier, F.; Tossou, M. C.; Rahu, N. Oxidative Stress and Inflammation: What Polyphenols Can Do for Us?. Oxid. Med. Cell Longev. 2016, 2016, 7432797, https://doi.org/10.1155/2016/7432797.

24. Maisetta, G.; Batoni, G.; Caboni, P.; Esin, S.; Rinaldi, A.C.; Zucca, P. Tannin profile, antioxidant properties, and antimicrobial activity of extracts from two Mediterranean species of parasitic plant Cytinus. BMC Complement Altern. Med. 2019, 19, 82, https://doi.org/10.1186/s12906-019-2487-7.

25. Asfar, A.A.; Zaheer, Z.; Aazam, E.S. Eco-friendly green synthesis of Ag@Fe bimetallic nanoparticles: antioxidant, antimicrobial and photocatalytic degradation of bromothymol blue. J. Photo. Chem. Photobiol. B. Biol. 2018, 185, 143-152, https://doi.org/10.1016/j.jphotobiol.2018.05.028.

26. Shahinuzzaman, M.; Yaakob, Z.; Anuar, F. H.; Akhtar, P.; Kadir, N.; Hasan, A.; Sobayel, K.; Nour, M.; Sindi, H.; Amin, N.; Sopian, K.; Akhtaruzzaman, M. In vitro antioxidant activity of Ficus carica L. latex from 18 different cultivars. Sci. Rep. 2020, 10, 10852, https://doi.org/10.1038/s41598-020-67765-1.

27. Zhang, Y.; Leclercq, J.; Montoro, P. Reactive oxygen species in Hevea brasiliensis latex and relevance to Tapping Panel Dryness. Tree Physiol. 2017, 37, 261-269, https://doi.org/10.1093/treephys/tpw106.

28. Aljane, F; Neily, M.H.; Msaddak, A. Phytochemical Characteristics And Antioxidant Activity Of Several Fig (Ficus Carica L.) Ecotypes. Ital. J. Food Sci. 2020, 32, 755-768, https://doi.org/10.14674/IJFS.1884.

29. Devi, P.S.; Kumar, N.S.; Sabu, K.K. Phytochemical profiling and antioxidant activities of different parts of Artocarpus heterophyllus Lam. (Moraceae): A review on current status of knowledge. Futur. J. Pharm. Sci. 2021, 7, 30, https://doi.org/10.1186/s43094-021-00178-7.

30. Teka, T.; Kassahun, H. Characterization and Evaluation of Antioxidant Activity of Aloe schelpei Reynolds. Drug Des. Devel. Ther. 2020, 14, 1003-1008, https://doi.org/10.2147/DDDT.S241412.

31. Kaparakou, E.H., Kanakis, C.D., Gerogianni, M., Maniati, M., Vekrellis, K., Skotti, E.; Tarantilis, P.A. Quantitative determination of aloin, antioxidant activity, and toxicity of Aloe vera leaf gel products from Greece. J. Sci. Food Agric. 2021, 101, 414-423, https://doi.org/10.1002/jsfa.10650.

32. Klaikeaw, N.; Wongphoom, J.; Werawatganon, D.; Chayanupatkul, M.; Siriviriyakul, P. Anti-inflammatory and antioxidant effects of aloe vera in rats with non-alcoholic steatohepatitis. World J. Hepatol. 2020, 12, 363-377, https://doi.org/10.4254/wjh.v12.i7.363.

33. Smeriglio, A.; Ragusa, S.; Monforte, M.T.; D'angelo, V.; Circosta, C. Phytochemical analysis and evaluation of antioxidant and anti-acetylcholinesterase activities of Euphorbia dendroides L. (Euphorbiaceae) latex. Plant Biosyst. 2019, 153, 498-505, https://doi.org/10.1080/11263504.2018.1498405.

34. Sharma, A.; Bachheti, A.; Sharma, P.; Bachheti, R.K.; Husen, A. Phytochemistry, pharmacological activities, nanoparticle fabrication, commercial products and waste utilization of Carica papaya L.: A comprehensive review. Curr. Res. Biotechnol. 2020, 2, 145-160, https://doi.org/10.1016/j.crbiot.2020.11.001.

35. Siritapetawee, J.; Thammasirirak, S.; Samosornsuk, W. Antimicrobial activity of a 48-kDa protease (AMP48) from Artocarpus heterophyllus latex. Eur. Rev. Med. Pharmacol. Sci. 2012, 16, 132-137.

36. Shuaib, M.; Ali, A.; Ali, M.; Panda, B. P.; Ahmad, M. I. Antibacterial activity of resin rich plant extracts. $J$. Pharm. Bioallied Sci. 2013, 5, 265-269, https://doi.org/10.4103/0975-7406.120073.

37. Bahmani, M.; Rafieian-Kopaei, M.; Hassanzadazar, H.; Taherikalani, M. Pseudomoniasis phytotherapy: a review on most important Iranian medicinal plants effective on Pseudomonas aeruginosa. Iran. J. Microbiol. 2016, 8, 347-350.

38. Keweloh, H.; Diefenbach, R.; Rehm, H.J. Increase of phenol tolerance of Escherichia coli by alterations of the fatty acid composition of the membrane lipids. Arch. Microbiol. 1991, 157, 49-53, https://doi.org/10.1007/BF00245334.

39. Smirnova, G.; Samoylova, Z.; Muzyka, N.; Oktyabrsky, O. Influence of polyphenols on Escherichia coli resistance to oxidative stress. Free Radic. Biol. Med. 2009, 46, 759-768, https://doi.org/10.1016/j.freeradbiomed.2008.11.017. 
40. Eve, A.; Aliero, A.A.; Nalubiri, D.; Adeyemo, R.O.; Akinola, S.A.; Pius, T.; Nabaasa, S.; Nabukeera, S.; Alkali, B.; Ntulume, I. In Vitro Antibacterial Activity of Crude Extracts of Artocarpus heterophyllus Seeds against Selected Diarrhoea-Causing Superbug Bacteria. Sci. World J. 2020, 2020, 9813970, https://doi.org/10.1155/2020/9813970.

41. Vázquez-González, Y.; Ragazzo-Sánchez, J.A.; Calderón-Santoyo, M. Characterization and antifungal activity of jackfruit (Artocarpus heterophyllus Lam.) leaf extract obtained using conventional and emerging technologies. Food Chem. 2020, 330, 127211, https://doi.org/10.1016/j.foodchem.2020.127211.

42. Ramli, A.; Badrulzaman, S.; Hamid, H.; Bhuyar, P. Antibacterial and antioxidative activity of the essential oil and seed extracts of Artocarpus heterophyllus for effective shelf-life enhancement of stored meat. J. Food Process Preserv. 2020, 45, e14993, https://doi.org/10.1111/jfpp.14993.

43. Prastiyanto, M.E.; Tama, P.D.; Ananda, N.; Wilson, W.; Mukaromah, A.H. Antibacterial Potential of Jatropha sp. Latex against Multidrug-Resistant Bacteria. Int. J. Microbiol. 2020, 2020, 8509650, https://doi.org/10.1155/2020/8509650.

44. Pruthvi, M.L.; Mahesh, M.K.; Mary, R.S. Efficacy Of Euphorbia Heterophylla Latex Against Pathogenic Bacteria And Fungi. Asian J. Pharm. Clin. Res. 2020, 13, 141-145, https://doi.org/10.22159/ajpcr.2020.v13i6.37341. 